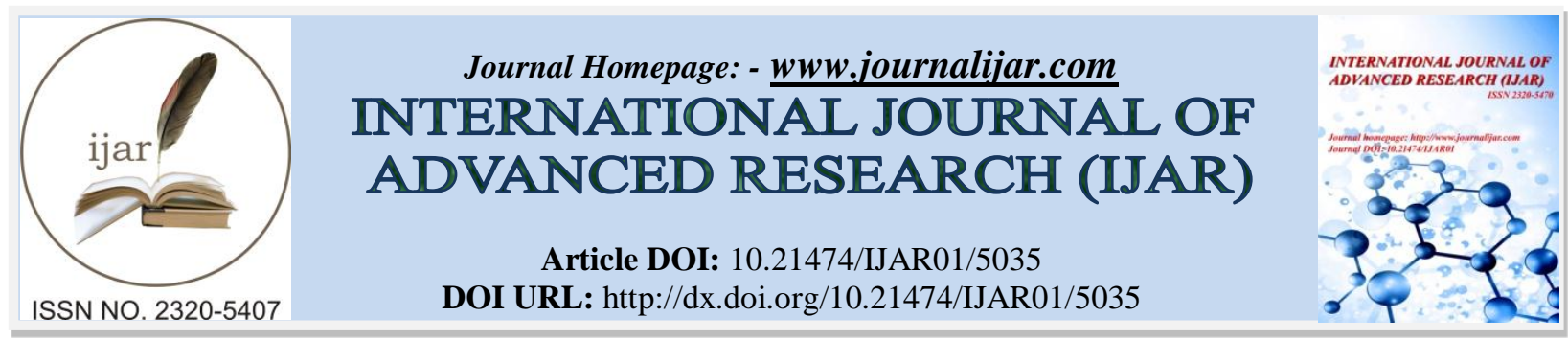

RESEARCH ARTICLE

\title{
STUDY OF DRY EYE IN UNDIAGNOSED POPULATION OF WESTERN PART OF INDIA. DRY EYE TIP OF ICEBERG?
}

\author{
Dr. Pradeep Dindore ${ }^{1}$ and Dr. Siddhesh R. Salvi ${ }^{2}$. \\ 1. Associate professor, D.Y.Patil Hospital Kolhapur. \\ 2. MS Ophthalmology, Mumbai.
}

\section{Manuscript Info}

Manuscript History

Received: 01 June 2017

Final Accepted: 03 July 2017

Published: August 2017

Key words:-

Dry eye, Keratoconjunctivitis sicca,

Schirmer Test.

\section{Abstract}

Keratoconjunctivitis sicca (KCS), dry eye syndrome, has been changed over recent years. Until lately, the condition was thought to be due to aqueous tear insufficiency. Today, it is understood that KCS is a multifactorial disorder due to inflammation of the ocular surface and lacrimal gland, neurotrophic deficiency and meibomian gland dysfunction.

Copy Right, IJAR, 2017,. All rights reserved.

\section{Introduction:-}

Dry eye disease is a multifactorial disease of the tear film and ocular surface that results in symptoms of discomfort, visual disturbance, and tears film instability with potential damage to the ocular surface. It is accompanied by increased osmolality of tear film and inflammation of the ocular surface. ${ }^{[2]}$.

Dry eye disease(DED) is a common and chronic condition, which is considered a major health concern internationally.It causes eye discomfort and pain and reduces quality of life(Reddy et all 2004)

\section{Prevalence:-}

Previous studies on prevalence of DED showed markedly variable results partly due to the different disease definitions used in these studies and lack of single validated test or combination of test to confirm diagnosis.All above mentioned studies are on patients attending out patient department with chief complaints of dry eye.

Prevalence of dry eye disease range from $5 \%$ to $30 \%$ over the age of fifty.

There is no study in India on undiagnosed dry eye patients who came to OPD for either routine eye check-up or who were not complaining typical symptoms of Dry eye.

However, there are only three published reports on prevalence of dry eye among hospital-based population from North and Eastern India and the prevalence varies between $18.4 \%$ and $40.8 \%{ }^{[1]}$

\section{Objectives:-}

- To establish the diagnosis of dry eye and to differentiate it from other causes of irritation

- To prevent complications, such as loss of visual function, infection, and structural damage. 
Methodology-

Source Of Data- D.Y.Patil Hospital, Kadamwadi, Kolhapur.

Ophthalmology Department.

We have done my study in asymptomatic patients, who don't have typical symptoms of dry eye such as gritty feeling in eyes, sensitivity to light, painful eyes and soar eyes. Total 300 patients whom we have attended who came to ophthalmic OPD of D.Y.Patil Hospital, Kolhapur for diminution of vision,refractive errors, routine eye checking, diabetic or hypertensive patients for retina examination. In every single patient I have done Schirmer test, surprisingly out of $\mathbf{3 0 0}$ patients $\mathbf{7 0}$ patients had dry eye.

Schirmer Test procedure- we Switched off the fans. Patient were seated in chair in a dim light room.We did not use any eye drops, remove excess moisture from patients eye lids, fold sterile Schirmer's paper at the mark, told the patients to look-up and pulled the lower lid gently down-ward temporally. Used sterile technique to get Schirmer's paper from the cover and bend the end of the sterile strip at $5 \mathrm{~mm}$ mark. It was kept in lateral 1/3 of the lower lid margin and took precaution of not get touched to the cornea. After 5 minutes, We removed the strip from the eye and measured the length of the moistened area using the millimeter scale on the strip.The bent part is not included in the final measurement.

Depending upon wetting $5 \mathrm{~mm}$ or 5 to $10 \mathrm{~mm}$ or 10 to $15 \mathrm{~mm}$, patients were grouped under severe moderate or mild dry eye.

we advised patients of mild dry eyes to use lubricating eye drops, Moderate dry eyes patients to use lubricating eye drops and cyclosporine eye drop, Severe dry eyes patients to use lubricating eye drops, cyclosporine eye drop and Cap. Omega 3-fatty acid.

Study Report:-

Total patients that we have studied are 300 out of which the patients who diagnosed with dry eye are 70 .

Total incidence that we have found in my study is $23.33 \%$.

\section{Incidence of Dry eye}

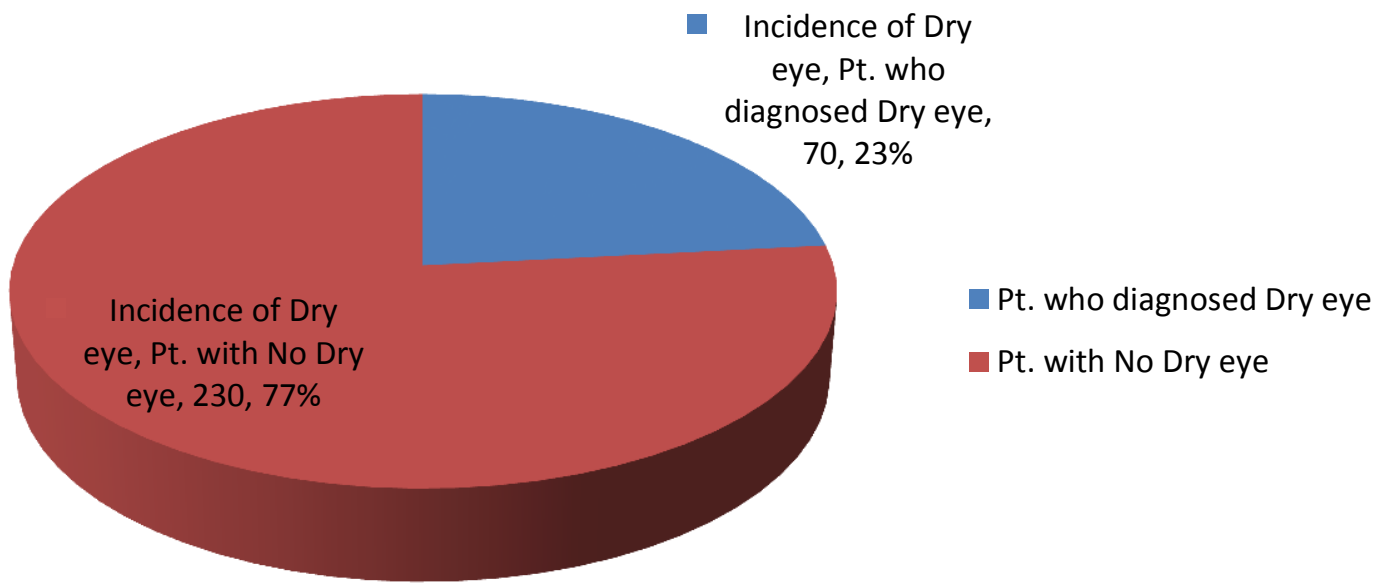


- Incidence of Dry eye according to the Age of patient.

\begin{tabular}{|l|l|}
\hline Age of patient & Patients who diagnosed as Dry eye \\
\hline 0 -20 years & 0 \\
\hline $20-40$ years & 3 \\
\hline $40-60$ years & 27 \\
\hline $60-80$ years & 34 \\
\hline above 80 years & 6 \\
\hline
\end{tabular}

- Incidence of dry eye according to the gender of patient

\begin{tabular}{|l|l|}
\hline SEX & Patients who diagnosed as Dry eye \\
\hline Male & 28 \\
\hline Female & 42 \\
\hline
\end{tabular}

\section{patients who diagnosed with dry eye according to the gender of patient}

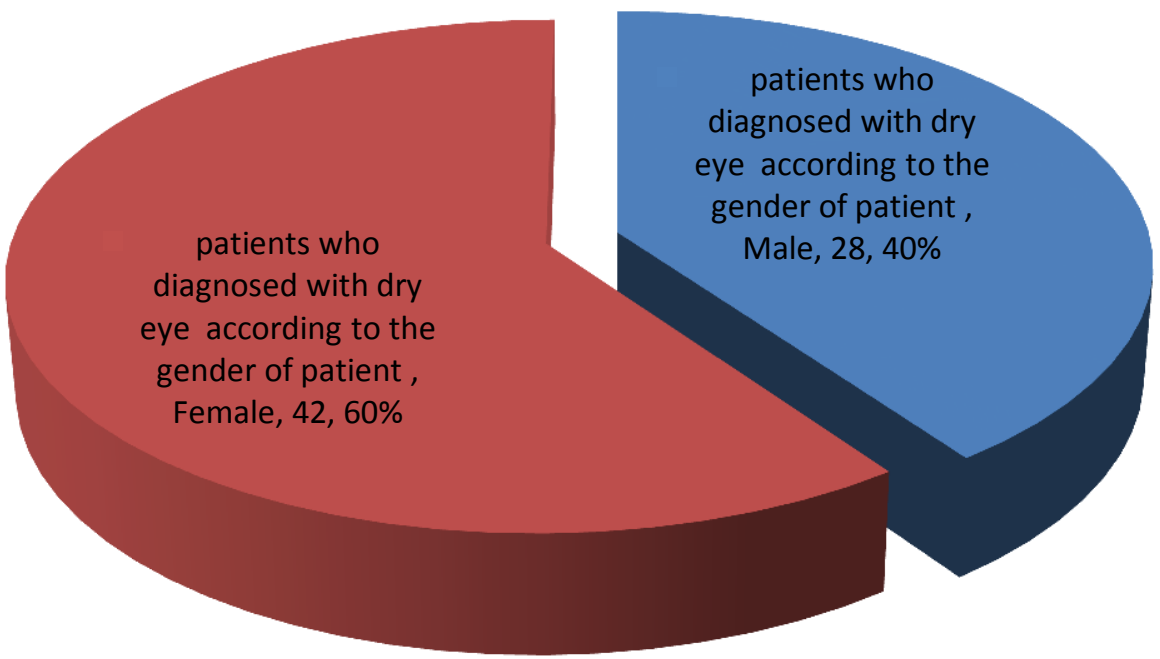

- Incidence of dry eye according to severity

\begin{tabular}{|l|c|}
\hline Severity of dry eye \\
\hline Mild \\
\hline Moderate \\
\hline Severe
\end{tabular}

Severe

26

Incidence of dry eye according to severity 

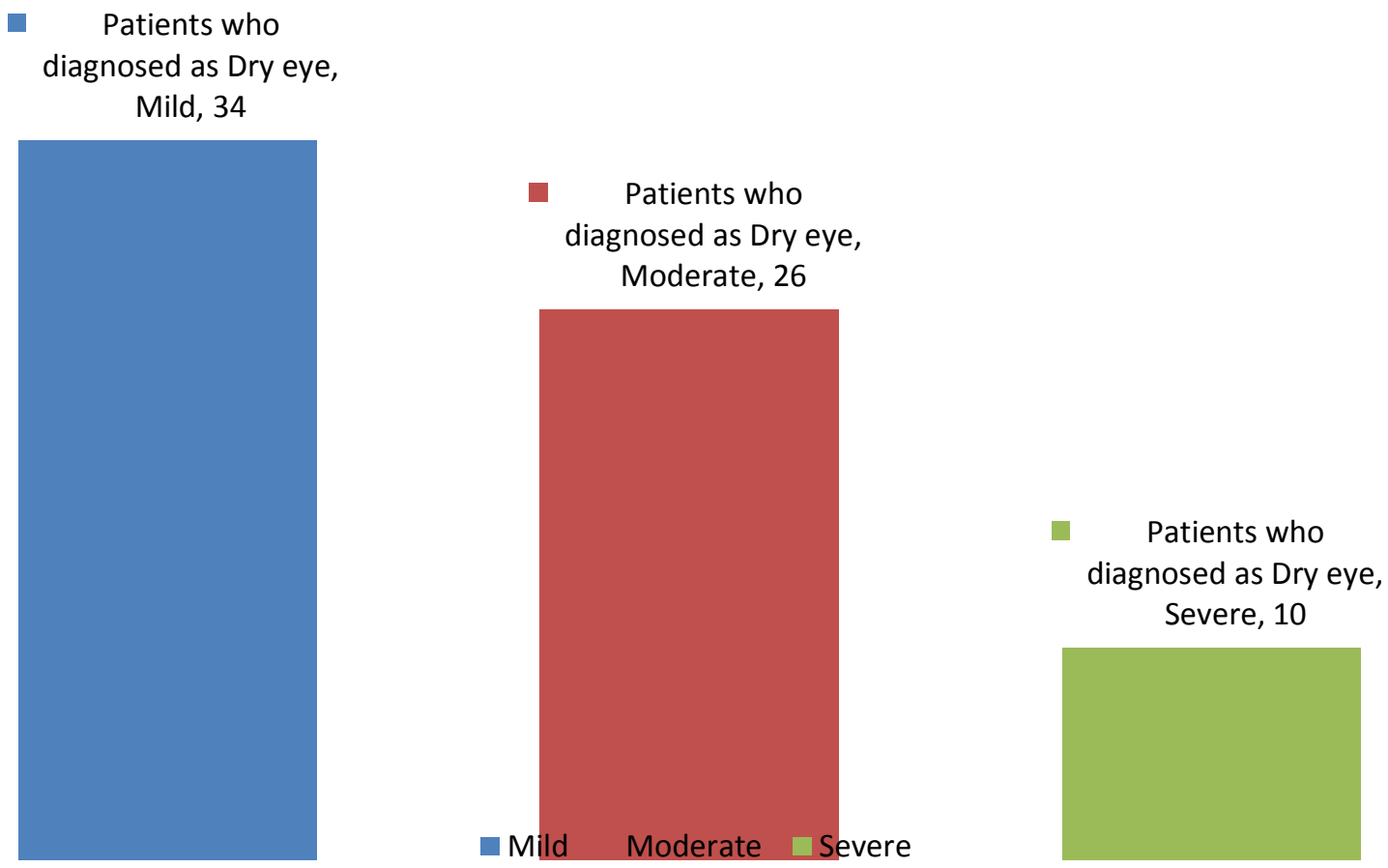

- Incidence of dry eye according to Ocupation

\begin{tabular}{|l|l|}
\hline Occupation & Dry eye patients \\
\hline Farmers & 47 \\
\hline Factory-workers & 17 \\
\hline Non-workers & 4 \\
\hline Others & 2 \\
\hline
\end{tabular}

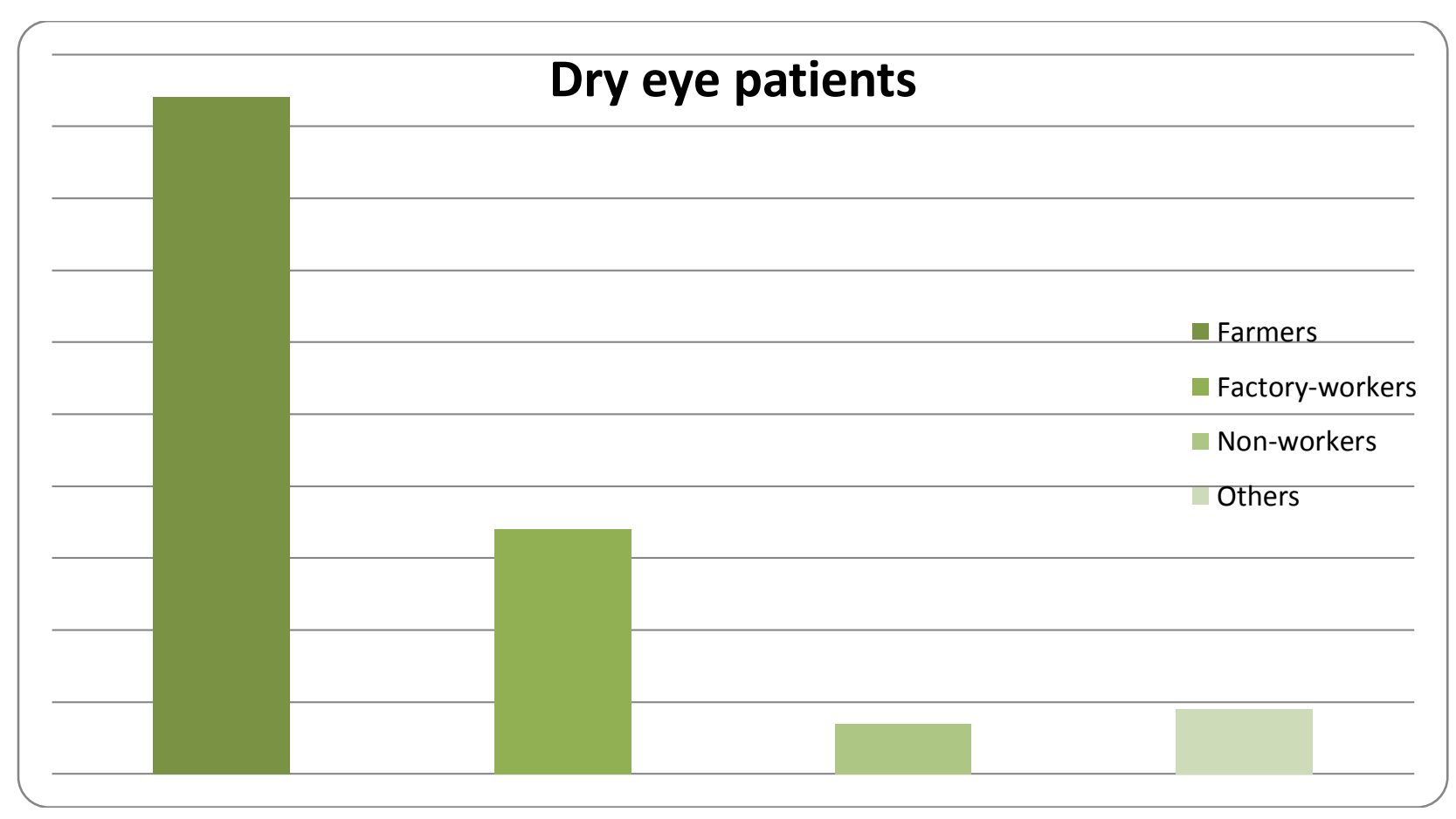




\section{Result:-}

We have found in my study, the incidence of dry eye is $23.33 \%$ in undiagnosed Indian population.

The incidence of dry eye is more in peoples who are out field workers like farmers and female population has more incidence of dry eye as compaired to male population.

\section{Conclusion:-}

From our study it shows that it is very important to do the Schirmers test in every individual specially the person who is living in a tropical country like India.

It will prevent complications, such as loss of visual function, infection, and structural damage to eye.

\section{Discussion:-}

In our study, dry eye incidence increased progressively with age.

In our study, it is also found that the dry eye incidence is higher in female population and in out-field workers like farmers.

Past studies suggest that dry eye prevalence ranges from $10.8 \%$ to $57.1 \% \cdot{ }^{[3-5]}$ The vast disparity in dry eye prevalence stems mainly from the different dry eye diagnostic criteria employed and different cut-off values for objective dry eye tests.

Exposure to excessive wind, sunlight/high temperature and drugs were significantly related to dry eye causation.

\section{References:-}

1. Anshu Sahai, Pankaj Malik, Dry Eye: Prevalence and Attributable Risk Factors in a Hospital-Based Population,Ijo 2005,53(2) pg.no. 87-91.

2. Report of the International Dry eye Workshop (DEWS). (Special issue) Ocul Surf 2007; 5: 65-199.

3. Hikichi T, Yoshida A, Fukui Y, Hamano T, Ri M, Araki K, et al . Prevalence of dry eye in Japanese eye centers. Graefes Arch Clin Exp Ophthalmol 1995;233:555-8.

4. Farrell J, Grierson DJ, Patel S, Sturrock RD. A classification for dry eyes following comparison of tear thinning time with Schirmer tear test. Acta Ophthalmol (Copenh) 1992;70:357-60.

5. Toda I, Fujishima H, Tsubota K. Ocular fatigue is the major symptom of dry eye. Acta Ophthalmol (Copenh) 1993;71:347-52. 